\title{
The Italian version of the Pain Beliefs and Perceptions Inventory: cross-cultural adaptation, factor analysis, reliability and validity
}

\author{
Marco Monticone $\cdot$ Simona Ferrante $\cdot$ \\ Silvano Ferrari $\cdot$ Calogero Foti $\cdot$ Raffaele Mugnai $\cdot$ \\ Paolo Pillastrini $\cdot$ Barbara Rocca $\cdot$ Carla Vanti
}

Accepted: 30 December 2013

(C) Springer Science+Business Media Dordrecht 2014

\begin{abstract}
Purpose To create an Italian version of the Pain Beliefs and Perceptions Inventory (PBAPI-I) and evaluate its psychometric properties.

Methods The PBAPI was culturally adapted in accordance with international standards. The psychometric testing included factor analysis, investigating reliability by internal consistency (Cronbach's alpha) and test/retest stability (intraclass correlation coefficient, ICC), and exploring construct validity by comparing the PBAPI-I with a pain numerical rating scale (NRS), the Roland Morris Disability Questionnaire (RMDQ), the Pain Catastrophizing Scale (PCS), the Tampa Scale of Kinesiophobia (TSK), the Hospital Anxiety and Depression Score (HADS) and the Chronic Pain Coping Inventory (Pearson's correlation).

Results One hundred and sixty-seven subjects with chronic low back pain ( $83 \%$ compliance) completed the tool. Factor
\end{abstract}

IRB approval The Institutional Review Board of the Salvatore Maugeri Foundation's Scientific Institute in Lissone approved the study, which was conducted in conformity with ethical and humane principles of research.

M. Monticone $(\square) \cdot$ B. Rocca

Physical Medicine and Rehabilitation Unit, Scientific Institute of Lissone (Milan), Institute of Care and Research, Salvatore

Maugeri Foundation IRCCS, Via Monsignor Bernasconi 16,

20035 Lissone, Milan, Italy

e-mail: marco.monticone@fsm.it

\section{S. Ferrante}

Neuroengineering and Medical Robotics Laboratory,

Department of Electronics, Information and Bioengineering,

Politecnico di Milano, Milan, Italy

S. Ferrari

Department of Biomedical Sciences, University of Padua, Padua, Italy analysis revealed a three-factor (Time, Mystery and SelfBlame), 16-item solution (explained variance: $80 \%$ ). The questionnaire was internally consistent $(\alpha=0.91-0.96)$, and its stability was good (ICCs $=0.73-0.82$ ). As expected, the construct validity estimates indicated that the Time and Mystery subscales moderately correlated with the NRS $(r=0.33-0.54)$, RMDQ $(r=0.34-0.47)$, PCS $(r=0.37-0.49)$ and TSK $(r=0.30-0.43)$, whereas the correlations between the SelfBlame subscale and the same measures were poorer. The correlations with the HADS were moderate and poor (anxiety: $r=0.37-0.05$; depression: $r=0.39-0.07$ ). Maladaptive coping strategies were more related to pain beliefs than adaptive strategies.

Conclusion The PBAPI-I has good psychometric properties that replicate those of other versions.

Keywords Pain Beliefs and Perceptions Inventory · Low back pain - Exploratory factor analysis . Psychometric properties - Italian validation

\section{Foti}

Physical and Rehabilitation Medicine, Tor Vergata University of Rome, Rome, Italy

\section{R. Mugnai}

Department of Orthopedics, University Hospital of Modena, University of Modena and Reggio Emilia, Modena, Italy

P. Pillastrini - C. Vanti

Department of Biomedical and Neuromotor Sciences

(DIBINEM), University of Bologna, Bologna, Italy 


\begin{tabular}{|c|c|}
\hline \multicolumn{2}{|c|}{ Abbreviations } \\
\hline CI & Confidence interval \\
\hline CPCI & Chronic Pain Coping Inventory \\
\hline EFA & Exploratory factor analysis \\
\hline HADS & Hospital Anxiety and Depression Score \\
\hline HADS-A & $\begin{array}{l}\text { Hospital Anxiety and Depression Score- } \\
\text { Anxiety }\end{array}$ \\
\hline HADS-D & $\begin{array}{l}\text { Hospital Anxiety and Depression Score- } \\
\text { Depression }\end{array}$ \\
\hline ICC & Intraclass correlation coefficient \\
\hline ISPOR & $\begin{array}{l}\text { International Society for Pharmacoeconomics } \\
\text { and Outcomes Research }\end{array}$ \\
\hline LBP & Low back pain \\
\hline NIDDM & Non-insulin-dependent diabetes mellitus \\
\hline Nos & Numbers \\
\hline NRS & Numerical Rating Scale \\
\hline NSAIDs & Non-steroidal anti-inflammatory drugs \\
\hline PBAPI & Pain Beliefs and Perceptions Inventory \\
\hline PBAPI-I & $\begin{array}{l}\text { Pain Beliefs and Perceptions Inventory, Italian } \\
\text { version }\end{array}$ \\
\hline PBs & Pain beliefs \\
\hline PCS & Pain Catastrophizing Scale \\
\hline $\mathrm{R}$ & Pearson's correlation \\
\hline RMDQ & Roland Morris Disability Questionnaire \\
\hline $\mathrm{SD}$ & Standard deviation \\
\hline SOPA & Survey of Pain Attitudes \\
\hline TSK & Tampa Scale of Kinesiophobia \\
\hline & Cronbach's alpha \\
\hline
\end{tabular}

\section{Introduction}

Unhelpful beliefs concerning chronic pain often lead to increased pain perception, maladaptive behaviours, a poorer physical condition and worse treatment responses [1]. Cognitive-behavioural approaches increasingly encourage subjects with chronic pain to become aware of these beliefs in order to regulate their feelings and maladaptive reactions, and develop better ways of dealing with their situation [2].

A variety of measures have been developed to address the need for a reliable and valid assessment of thoughts related to chronic pain, including the Pain Beliefs and Perceptions Inventory (PBAPI) [1] and the Survey of Pain Attitudes (SOPA) [3]. The former primarily attracted our attention because it has proven to be an easy and rapidly administered measure for identifying cognitive factors that may benefit from cognitive-behaviourally oriented treatments.

The PBAPI, which was developed in 1989 by soliciting beliefs about pain from injured workers with chronic complaints [1], was originally deemed to have a threefactor solution identifying subscales representing time (pain is an enduring part of life), mystery (pain is poorly understood) and Self-Blame (patients attribute the responsibility for their pain to themselves), although other studies involving Australian, German, American and British populations supported a four-factor structure by splitting the Time subscale into two parts, Constancy and Permanence [4-7]. The PBAPI is reliable, and satisfactory correlates with measures of pain, disability, psychological disturbances and coping strategies.

As a fully cross-cultural Italian version of the PBAPI has not been developed and psychometrically analysed, Italian researchers and clinicians are limited in sharing validated outcomes. The aim of this study was to develop a culturally adapted and validated Italian version of the PBAPI for use in subjects with chronic low back pain (LBP).

\section{Methods}

This cross-sectional study was approved by our Institutional Review Board, and the patients gave their written consent.

Subjects

The study involved outpatients attending the rehabilitation unit of our hospital and three affiliated centres between June 2011 and December 2012, whose demographic and clinical characteristics were recorded by research assistants. The inclusion criteria were chronic non-specific LBP, an age of $>18$ years, and fluency in Italian; the exclusion criteria were acute and subacute LBP, central or peripheral neurological signs, systemic illness, mental deficits, recent cerebrovascular accidents or myocardial infarctions, and chronic lung or renal diseases.

\section{PBAPI}

This is a 16-item questionnaire and patients rate their beliefs using a 4-point Likert scale ranging from -2 (total disagreement) to +2 (total agreement); item Nos. 3, 9, 12 and 15 are reverse scored. For each subscale, the scores of the responses to the items that are answered are added and divided by the number of items answered; higher scores indicate greater endorsement of the belief [1].

Cross-cultural adaptation

This was done in accordance with the protocol issued by the American Association of Orthopedic Surgeon Outcomes Committee [8], taking into account the principles described in the ISPOR task force report "Principles of Good Practice for the Translation and Cultural Adaptation Process for Patient-Reported Outcomes (PRO) Measures" [9]. 
Step 1: Translation into Italian The items taken from the original PBAPI were translated into Italian with the aim of retaining the concepts of the original while using culturally and clinically fitting expressions. Two translations were made independently by two professional Italian translators experienced in the PRO field. The translators were given a clear explanation of the concepts in the PBAPI in order to capture the conceptual meaning of the items. Keeping the language colloquial and compatible with a reading age of 14 years, the discrepancies in the translations were resolved by means of reconciliation between the translators; step 1 ended when a common adaptation was agreed.

Step 2: Back-translation into English Two bilingual translators whose mother tongue was English independently back-translated the initial translation. The principal investigator (MM) reviewed these translations and, with the help of the back-translators, ensured that the Italian version reflected the same item content as the original version and was conceptually equivalent.

Step 3: Expert Committee In order to harmonize the adaptation process, the translations were submitted to a bilingual committee of clinicians, methodologists and the translators chaired by the principal investigator, who explored the semantic, idiomatic and conceptual equivalence of the items and answers to identify any discrepancies or mistakes. This phase ended when a pre-final version was agreed.

Step 4: Test of the pre-final version The pre-final version was tested in order to assess the comprehensibility and cognitive equivalence of the translation, highlight any items that may be inappropriate at conceptual level and identify any other issues that may cause confusion. This was done by means of cognitive interviews conducted by a trained psychologist (BR) who administered the PBAPI to 30 patients with chronic LBP. The principal investigator and Expert Committee reviewed the results of the cognitive debriefing with the aim of identifying any modification necessary to improve the Italian form.

\section{Sample size}

This was based on the "rule of 10" patients per item [10].

Scale properties

\section{Feasibility}

The time needed to answer the questionnaire was recorded. The patients were asked about any problems they encountered, and the data were checked for missing or multiple responses.

\section{Factor analysis}

As the PBAPI had not been previously investigated in this population, its structure was analysed by exploratory factor analysis (EFA), using Cattel's Scree Test to determine the number of extracted factors (eigenvalues of $>1$ ). Varimax rotation was applied, and the items with factor loadings of $>0.40$ were included in the factor. The expected explained variance was $>50 \%[10]$.

\section{Floor/ceiling effects}

Descriptive statistics were calculated to identify floor/ ceiling effects, which were considered to be present when $>15 \%$ of the subjects obtained the lowest or highest possible scores [10].

\section{Reliability}

This was tested by internal consistency (Cronbach's alpha, with values of $>0.70$ being considered acceptable) and testretest stability (intraclass correlation coefficient: ICC 2,1, with good and excellent reliability respectively indicated by values of $0.70-0.85$ and $>0.85$ ) [10]. Stability was investigated by administering the scale to the same subjects after 7 days.

\section{Content validity}

This was based on the patients' answers to specific questions investigating the aim of the measurement (Question: "Do you think the aim of this questionnaire is pain beliefs (PBs)?"), the target population ("Do you think the items described here may be related to your pain?"), relevance ("Do you think these items are relevant to evaluating your PBs?") and completeness ("Do you think that the items comprehensively reflect your PBs?"). The hypotheses were considered acceptable if the percentage of affirmative answers was $>90 \%$ [10].

\section{Construct validity}

This was investigated by testing the hypotheses using outcome measures as detailed below [10]. It was hypothesized a priori there would be moderate correlations between the PBAPI subscales eventually resulting from the factor analysis and a measure of pain intensity, the 0-10 numerical rating scale (NRS) [11], a measure of disability, the Italian version of the Roland Morris Disability Questionnaire (RMDQ) [12], a measure of catastrophizing, the Italian version of the Pain Catastrophizing Scale (PCS) [13] and a measure of kinesiophobia, the Italian version of the Tampa Scale of Kinesiophobia (TSK) [14]; moderate-poor correlations with a measure of mood disorders, the Italian version 
Table 1 Sociodemographic characteristics of the population $(n=167)$

\begin{tabular}{|c|c|c|}
\hline Variable & Nos. & Percent \\
\hline \multicolumn{3}{|l|}{ Marital status } \\
\hline Unmarried & 58 & 34.7 \\
\hline Married & 109 & 65.3 \\
\hline \multicolumn{3}{|l|}{ Occupation } \\
\hline Employee & 82 & 49.1 \\
\hline Self-employed & 37 & 22.2 \\
\hline Housewife & 19 & 11.4 \\
\hline Pensioner & 29 & 17.3 \\
\hline \multicolumn{3}{|l|}{ Education } \\
\hline Primary school & 21 & 12.6 \\
\hline Middle school & 34 & 20.4 \\
\hline High school & 73 & 43.7 \\
\hline University & 39 & 23.3 \\
\hline \multicolumn{3}{|l|}{ Smoking } \\
\hline Yes & 23 & 13.8 \\
\hline No & 144 & 86.2 \\
\hline \multicolumn{3}{|l|}{ Drug use } \\
\hline Antidepressants & 21 & 12.6 \\
\hline Analgesics & 62 & 37.1 \\
\hline Muscle relaxants & 18 & 10.8 \\
\hline NSAIDs & 47 & 28.1 \\
\hline None & 19 & 11.4 \\
\hline \multicolumn{3}{|c|}{ Comorbidities (principal) } \\
\hline Hypertension & 43 & 25.7 \\
\hline NIDDM & 14 & 8.4 \\
\hline Heart disease & 19 & 11.4 \\
\hline Enteric disease & 12 & 7.2 \\
\hline Liver disease & 9 & 5.4 \\
\hline None & 70 & 41.9 \\
\hline
\end{tabular}

NSAIDs non-steroidal anti-inflammatory drugs, NIDDM non-insulindependent diabetes mellitus

of the Hospital Anxiety and Depression Score (HADS) [15]; and moderate-poor correlations with a measure of coping, the Italian version of the Chronic Pain Coping Inventory (CPCI) [16] (moderate with maladaptive and poor with adaptive strategies). Pearson's correlations: $r<0.30=$ low; $0.30<r<0.60=$ moderate; $r>0.60=$ high. Construct validity was considered good if $>75 \%$ of the hypotheses were confirmed.

The analyses were made using SPSS 20.0 software.

\section{Results}

Subjects

A total of 202 patients were invited to participate, of whom 167 accepted: 93 females $(55.68 \%)$ and 74 males
Table 2 Factor analysis loadings of the PBAPI

\begin{tabular}{|c|c|c|c|}
\hline & \multicolumn{3}{|l|}{ Factors } \\
\hline & Time & Mystery & $\begin{array}{l}\text { Self- } \\
\text { Blame }\end{array}$ \\
\hline $\begin{array}{l}\text { 2. I used to think my pain was curable } \\
\text { but now I'm not so sure }\end{array}$ & 0.884 & 0.187 & 0.046 \\
\hline 3. There are times when I am pain free & 0.891 & 0.115 & 0.013 \\
\hline 5. My pain is here to stay & 0.852 & 0.168 & -0.074 \\
\hline 6. I am continuously in pain & $\mathbf{0 . 8 2 7}$ & 0.181 & -0.172 \\
\hline $\begin{array}{l}\text { 9. My pain is a temporary problem in } \\
\text { my life }\end{array}$ & 0.854 & 0.041 & -0.058 \\
\hline $\begin{array}{l}\text { 10. It seems like I wake up with pain } \\
\text { and I go to sleep with pain }\end{array}$ & 0.862 & 0.216 & 0.032 \\
\hline 12. There is a cure for my pain & 0.848 & 0.008 & 0.004 \\
\hline $\begin{array}{l}15 . \text { Someday I'll be } 100 \% \text { pain free } \\
\text { again }\end{array}$ & 0.865 & 0.067 & 0.030 \\
\hline $\begin{array}{l}\text { 16. My pain varies in intensity but is } \\
\text { always with me }\end{array}$ & 0.877 & 0.189 & -0.063 \\
\hline $\begin{array}{l}\text { 1. No one's been able to tell me } \\
\text { exactly why I'm in pain }\end{array}$ & 0.207 & 0.887 & 0.041 \\
\hline 4. My pain is confusing to me & 0.145 & 0.869 & 0.089 \\
\hline 8. I don't know enough about my pain & 0.079 & 0.898 & 0.172 \\
\hline 14. I can't figure out why I'm in pain & 0.192 & 0.891 & 0.133 \\
\hline 7. If $I$ am in pain it is my own fault & -0.066 & 0.076 & 0.915 \\
\hline 11. I am the cause of my pain & -0.020 & 0.170 & 0.901 \\
\hline 13. I blame myself if I am in pain & -0.033 & 0.125 & 0.917 \\
\hline
\end{tabular}

Bold represent the best values resulting from the factor analysis

$(44.32 \%)$ with a mean age of $48.40 \pm 12.41$ years (range 20-71). The median duration of pain was 12 months (range 3-120). Table 1 shows their general characteristics.

Adaptation

The questionnaire was translated into Italian using a process of forward/backward translation involving four professional translators. All of the items were easily forward and backtranslated, and no difficulties were found during the review of the back-translations. A review by experts and the testing of the pre-final version confirmed the correctness of the process, the content of the items and the concepts expressed, and the cognitive interviews confirmed the comprehensibility and the cognitive equivalence of the translation without identifying anything causing confusion. Finally, the principal investigator and Expert Committee confirmed the work done.

PBAPI-I is in the "Appendix."

Scale properties

\section{Feasibility}

All of the questions were well accepted. The PBAPI-I was completed in $4.10 \pm 1.19 \mathrm{~min}$; there were no missing 
Table 3 Mean values, floor/ceiling effects and reliability of the PBAPI scales

\begin{tabular}{lllll}
\hline Subscales & Mean (SD) & $\begin{array}{l}\text { Floor/ } \\
\text { ceiling } \\
\text { effects } \\
(\%)\end{array}$ & $\begin{array}{l}\text { Internal } \\
\text { consistency } \\
(\alpha)\end{array}$ & $\begin{array}{l}\text { Test-retest (ICC } \\
\text { and 95 \% CI) }\end{array}$ \\
& & & \\
\hline
\end{tabular}

\section{PBAPI}

Time

$\begin{array}{lll}2.18(0.80) & 1.2 / 1.2 & 0.96 \\ 2.12(0.89) & 12 / 1.2 & 0.93 \\ 1.70(0.75) & 38.9 / 2.4 & 0.91\end{array}$

$0.81(0.75-0.86)$

Mystery

Self-

Blame

$\overline{S D \text { standard deviation, } \alpha \text { Cronbach's alpha, } I C C \text { intraclass correlation }}$ coefficient, $C I$ confidence interval

responses or multiple answers in any of the questionnaires, and no comprehension problems.

Prior to subsequent analysis, the response scale was recoded to ensure equal intervals (the current scale $-2,-1$, $+1,+2$ was recoded as $1,2,3,4)$ [7].

\section{Factor analysis}

EFA revealed a three-factor structure on the basis of the number of eigenvalues of $>1$ (the eigenvalues after vari$\max$ rotation were $6.807,3.389$ and 2.292), which explained $80 \%$ of the variance. The obtained structure replicated the original, and the subscales were called Time, Mystery and Self-Blame (Table 2 shows the factor

Table 4 Construct validity of the PBAPI scales

\begin{tabular}{llcc}
\hline Variables and subscales & Time & Mystery & Self-Blame \\
\hline Pain (NRS) & $0.54^{* *}$ & $0.33^{* *}$ & -0.04 \\
Disability (RMDQ) & $0.47^{* *}$ & $0.34^{* *}$ & -0.11 \\
Catastrophizing (PCS) & $0.49^{* *}$ & $0.37^{* *}$ & 0.02 \\
Kinesiophobia (TSK) & $0.43^{* *}$ & $0.30^{* *}$ & -0.01 \\
Anxiety (HADS-A) & $0.37^{* *}$ & $0.17^{*}$ & 0.05 \\
Depression (HADS-D) & $0.39^{* *}$ & 0.09 & -0.07 \\
Guarding (CPCI) & $0.37^{* *}$ & $0.36^{* *}$ & -0.11 \\
Resting (CPCI) & $0.32^{* *}$ & $0.30^{* *}$ & -0.13 \\
Asking for assistance (CPCI) & $0.34^{* *}$ & $0.35^{* *}$ & -0.01 \\
Relaxation (CPCI) & $0.19^{*}$ & $0.27^{* *}$ & 0.01 \\
Task persistence (CPCI) & $0.31^{* *}$ & -0.01 & $-0.21^{* *}$ \\
Exercise/stretching (CPCI) & 0.09 & 0.04 & $-0.19 *$ \\
Seeking social support (CPCI) & $0.35^{* *}$ & $0.37^{*}$ & $-0.16^{*}$ \\
Coping self-statements (CPCI) & 0.03 & 0.02 & -0.13 \\
\hline
\end{tabular}

NRS Numerical Rating Scale, $R M D Q$ Roland Morris Disability Questionnaire, PCS Pain Catastrophizing Scale; TSK Tampa Scale of Kinesiophobia, HADS-A Hospital Anxiety and Depression ScoreAnxiety, $H A D S-D$ Hospital Anxiety and Depression Score-Depression, $C P C I$ Chronic Pain Coping Inventory

$* * p<0.01 ; * p<0.05$ loadings after varimax rotation highlighting in bold the correspondence between items and factors). We also investigated a four-factor solution $[4-7,17]$ but the loadings associated with the fourth factor were always lower than 0.4 and always significantly lower than those associated with the other three factors. This confirmed the validity of the three-factor solution.

\section{Floor/ceiling effects}

Table 3 shows the descriptive statistics and ceiling/floor effects.

\section{Reliability}

Cronbach's $\alpha$ was excellent. Test-retest stability was measured in all the subjects, and the scales showed good ICCs (Table 3).

\section{Content validity}

The percentage of affirmative answers was always $>90 \%$.

\section{Construct validity}

This was good as $>75 \%$ of the a priori hypotheses were confirmed (Table 4). The Time and Mystery subscales moderately correlated with the NRS $(r=0.33-0.54)$, RMDQ $(r=$ $0.34-0.47)$, PCS $(r=0.37-0.49)$ and TSK $(r=0.30-0.43)$, whereas there were poorer correlations between the same measures and the Self-Blame subscale. The Time subscale moderately correlated with the HADS (anxiety: $r=0.37$; depression: $r=0.39$ ), whereas the correlations of the Mystery and Self-Blame subscales were poorer (anxiety: $r=$ 0.17-0.05; depression: $r=0.09-0.07$ ). The Time and Mystery subscales were more related to maladaptive coping strategies ( $r=0.34-0.37$ and $r=0.30-0.37)$ than adaptive strategies $(r=0.03-0.31$ and $r=0.01-0.27)$, whereas Self-Blame poorly related to both $(r=-0.16 ; 0.01$ and $r=-0.21 ; 0.01)$.

\section{Discussion}

The process of adaptation of the PBAPI-I guaranteed the meaning of the original items was adequately captured by the idiomatic translation. The questionnaire was acceptable and easily understood, and could be self-administered in about 5 min, making it applicable to everyday clinical practice.

The original three-factor structure was replicated, with strong factor loadings [1]. As other studies have suggested 
four-factor solutions [4-7, 17], we forced a four-factor solution on our data but found no improvement in factor loadings. Our three-factorial solution might be explained by the characteristics of the study sample and the previously uninvestigated context.

Internal consistency was excellent, with higher estimates than the original $(0.65-0.80)$, and Australian (0.67-0.80), English (0.80-0.89) and Chinese findings (0.60-0.76) [1, 4, $7,17]$. Test-retest stability was satisfactory but was not investigated in other samples, and so no comparisons are possible.

Correlation analyses showed that greater belief endorsement was associated with pain intensity, disability, catastrophizing, kinesiophobia, mood disorders and maladaptive coping strategies; these findings were consistent with those of previous studies [1, 4-7]. Self-Blame did not show the expected correlations probably because our sample was unfamiliar with cognitive-behavioural concepts; the high floor effect of this subscale confirmed the inability of the patients to interpret the items correctly. German and American studies have also questioned the correct interpretation of the correlations of Self-Blame, and further investigations are recommended $[5,6]$.

This study has some limitations: it did not consider relationships between pain beliefs and physical tests because only questionnaires were used, and, as it was restricted to chronic LBP, it is uncertain whether the findings can be extended to other chronic complaints; further analyses of the PBAPI-I should be carried out using patients with other chronic complaints. Content validity was based on questions that may have prevented neutral responses, thus partially limiting the soundness of our results; we therefore suggest using open questions in the future. Finally, we did not use some of the most established international measures used to carry out validation studies, such as the Brief Pain Inventory, the McGill Questionnaire and the SF-36 pain scale, but researchers are recommended to analyse them in future studies of the Italian PBAPI in order to investigate its properties further.

In conclusion, the PBAPI-I has good psychometric properties and can be recommended for use in chronic LBP research in Italy. This new measure is expected to help Italian clinicians and researchers in terms of diagnosis and therapy by identifying key chronic pain beliefs and providing additional clues for successful treatments that are more based on cognitive restructuring within the bio-psychosocial perspective.

Acknowledgments The authors would like to thank Kevin Smart for his help in preparing the English version of this paper.

\section{Appendix}

PBAPI: Pain Belief and Perceptions Inventory, Italian version

Per cortesia, indichi il grado con cui concorda o meno con ciascuna delle seguenti affermazioni. Faccia semplicemente un cerchio attorno al quadrato che corrisponde al suo livello di accordo.

\begin{tabular}{|c|c|c|c|c|}
\hline & $\begin{array}{l}\text { Totale } \\
\text { disaccordo }\end{array}$ & $\begin{array}{l}\text { Parziale } \\
\text { disaccordo }\end{array}$ & $\begin{array}{l}\text { Parziale } \\
\text { accordo }\end{array}$ & $\begin{array}{l}\text { Totale } \\
\text { accordo }\end{array}$ \\
\hline $\begin{array}{l}\text { 1. Nessuno è stato in } \\
\text { grado di spiegarmi } \\
\text { esattamente perché } \\
\text { provo dolore }\end{array}$ & $\square$ & $\square$ & $\square$ & $\square$ \\
\hline $\begin{array}{l}\text { 2. Pensavo che il mio } \\
\text { dolore fosse } \\
\text { curabile, ma ora } \\
\text { non ne sono più } \\
\text { così sicuro }\end{array}$ & $\square$ & $\square$ & $\square$ & $\square$ \\
\hline $\begin{array}{l}\text { 3. Ci sono momenti } \\
\text { in cui non ho } \\
\text { dolore* }\end{array}$ & $\square$ & $\square$ & $\square$ & $\square$ \\
\hline $\begin{array}{l}\text { 4. Il dolore mi } \\
\text { disorienta }\end{array}$ & $\square$ & $\square$ & $\square$ & $\square$ \\
\hline $\begin{array}{l}\text { 5. Il mio dolore è } \\
\text { persistente }\end{array}$ & $\square$ & $\square$ & $\square$ & $\square$ \\
\hline $\begin{array}{l}\text { 6. Provo } \\
\text { continuamente } \\
\text { dolore }\end{array}$ & $\square$ & $\square$ & $\square$ & $\square$ \\
\hline $\begin{array}{l}\text { 7. E' colpa mia se } \\
\text { provo dolore }\end{array}$ & $\square$ & $\square$ & $\square$ & $\square$ \\
\hline $\begin{array}{l}\text { 8. Non so abbastanza } \\
\text { del mio dolore }\end{array}$ & $\square$ & $\square$ & $\square$ & $\square$ \\
\hline $\begin{array}{l}\text { 9. Il dolore è un } \\
\text { problema } \\
\text { passeggero della } \\
\text { mia vita* }\end{array}$ & $\square$ & $\square$ & $\square$ & $\square$ \\
\hline $\begin{array}{l}\text { 10. Mi sembra di } \\
\text { svegliarmi con il } \\
\text { dolore e di andare a } \\
\text { dormire con il } \\
\text { dolore }\end{array}$ & $\square$ & $\square$ & $\square$ & $\square$ \\
\hline $\begin{array}{l}\text { 11. Io sono la ragione } \\
\text { del mio dolore }\end{array}$ & $\square$ & $\square$ & $\square$ & $\square$ \\
\hline $\begin{array}{l}\text { 12. Vi è una cura per } \\
\text { il mio dolore* }\end{array}$ & $\square$ & $\square$ & $\square$ & $\square$ \\
\hline $\begin{array}{l}\text { 13. Do la colpa a me } \\
\text { stesso se provo } \\
\text { dolore }\end{array}$ & $\square$ & $\square$ & $\square$ & $\square$ \\
\hline $\begin{array}{l}\text { 14. Non riesco a } \\
\text { capire perché provo } \\
\text { dolore }\end{array}$ & $\square$ & $\square$ & $\square$ & $\square$ \\
\hline
\end{tabular}


Appendix continued

\begin{tabular}{lllll}
\hline & $\begin{array}{l}\text { Totale } \\
\text { disaccordo }\end{array}$ & $\begin{array}{l}\text { Parziale } \\
\text { disaccordo }\end{array}$ & $\begin{array}{l}\text { Parziale } \\
\text { accordo }\end{array}$ & $\begin{array}{l}\text { Totale } \\
\text { accordo }\end{array}$ \\
\hline $\begin{array}{l}\text { 15. Un giorno mi } \\
\text { libererò } \\
\text { completamente dal } \\
\text { dolore* }\end{array}$ & $\square$ & $\square$ & $\square$ & $\square$ \\
$\begin{array}{l}\text { 16. Il mio dolore } \\
\text { varia di intensità, }\end{array}$ & $\square$ & $\square$ & $\square$ & $\square$ \\
ma è sempre con & & & \\
me & & & \\
\hline
\end{tabular}

\section{punteggio}

totale disaccordo $=-2 ;$ parziale disaccordo $=-1$; parziale accordo $=1$; totale accordo $=2$;

$*$ item inverso (totale accordo $=-2$; parziale accordo $=$ -1 ; parziale disaccordo $=1 ;$ totale disaccordo $=2$ )

Domini

Stabilità del dolore $(3,6,10,16,2,5,9,12,15)$ : ...; Il dolore come un mistero $(1,4,8,14)$ : ...

Autocolpevolizzazione $(7,11,13)$ : ...

\section{References}

1. Williams, D. A., \& Thorn, B. E. (1989). An empirical assessment of pain beliefs. Pain, 36, 351-358.

2. Jensen, M. P., Turner, J. A., \& Romano, J. M. (1994). Correlates of improvement in multidisciplinary treatment of chronic pain. Journal of Consulting and Clinical Psychology, 62, 172-179.

3. Jensen, M. P., Karoly, P., \& Huger, P. (1987). The development and preliminary validation of an instrument to assess patients' attitudes towards pain. Journal of Psychosomatic Research, 31, 393-400.

4. Strong, J., Ashton, R., \& Chant, D. (1992). The measurement of attitudes towards and beliefs about pain. Pain, 48, 227-236.

5. Herda, C. A., Siegeris, K., \& Basler, H. D. (1994). The Pain Beliefs and Perceptions Inventory: Further evidence for a 4-factor structure. Pain, 57, 85-90.
6. Williams, D. A., Robinson, M. E., \& Geisser, M. E. (1994). Pain beliefs: Assessment and utility. Pain, 59, 71-78.

7. Morley, S., \& Wilkinson, L. (1995). The Pain Beliefs and Perceptions Inventory: A British replication. Pain, 61, 427-433.

8. Beaton, D. E., Bombardier, C., Guillemin, F., \& Ferraz, M. B. (2000). Guidelines for the process of cross-cultural adaptation of self-report measures. Spine (Phila Pa 1976), 25, 3186-3189.

9. Wild, D., Grove, A., Martin, M., Eremenco, S., McElroy, S., Verjee-Lorenz, A., et al. (2005). Principles of good practice for the translation and cultural adaptation process for patient-reported outcomes (PRO) measures: Report of the ISPOR Task Force for Translation and Cultural Adaptation. Value Health, 8(2), 94-104.

10. Terwee, C. B., Bot, S., de Boer, M. R., van der Windt, D. A. W. M., Knol, D. L., Dekker, J., et al. (2007). Quality criteria were proposed for measurement properties of health status questionnaires. Journal of Clinical Epidemiology, 60, 34-42.

11. Huskinson, E. C. (1974). Measurement of pain. Lancet, 2, 1127-1131

12. Padua, R., Padua, L., Ceccarelli, E., Romanini, E., Zanoli, G., Bondì, R., et al. (2002). Italian version of the Roland disability questionnaire, specific for low back pain: Cross-cultural adaptation and validation. European Spine Journal, 11(2), 126-129.

13. Monticone, M., Baiardi, P., Ferrari, S., Foti, C., Mugnai, R., Pillastrini, P., et al. (2012). Development of the Italian version of the Pain Catastrophising Scale (PCS-I): cross-cultural adaptation, factor analysis, reliability, validity and sensitivity to change. Quality of Life Research, 21(6), 1045-1050.

14. Monticone, M., Giorgi, I., Baiardi, P., Barbieri, M., Rocca, B., \& Bonezzi, C. (2010). Development of the Italian version of the Tampa Scale of Kinesiophobia, TSK-I. Cross-cultural adaptation, factor analysis, reliability and validity. Spine (Phila $\mathrm{Pa}$ 1976), 35(12), 1241-1246.

15. Costantini, M., Musso, M., \& Viterbori, P. (1999). Detecting psychological distress in cancer patients: Validity of the Italian version of the hospital anxiety and depression scale. Supportive Care in Cancer, 7(3), 121-127.

16. Monticone, M., Ferrante, S., Giorgi, I., Galandra, C., Rocca, B., \& Foti, C. (2013). Development of the Italian version of the 42-item Chronic Pain Coping Inventory, CPCI-I: Cross-cultural adaptation, factor analysis, reliability and validity. Quality of Life Research, 22(6), 1459-1465.

17. Wong, W. S., Williams, D. A., Mak, K. H., \& Fielding, R. (2011). Assessing attitudes toward and beliefs about pain among Chinese patients with chronic pain: Validity and reliability of the Chinese version of the Pain Beliefs and Perceptions Inventory (ChPBPI). Journal of Pain and Symptoms Management, 42(2), 308-318. 